\title{
PROVISIONAL CONCLUSION
}

Reading a stack of books and countless articles on Trump and following his life closely since he has announced for presidency, I see Donald J. Trump as a paragon of what Herbert Marcuse called "one-dimensional man." 133 Trump's one-dimension is his gigantic ego that must be fed with unlimited amounts of adulation, money, power, and attention. His ego extends to his family that no doubt he sees as extensions of himself or part of his business enterprise (which they literarily are). Trump seems to have no life-long friends, no interests or hobbies beyond his business and now political enterprise, no interest in culture or ideas, beyond those he can exploit in his business or political campaign, and, as, biographers have noted, he does not seemed to be burdened with selfhood that involves depth, self-reflection, or selfawareness, let alone self-criticism, beyond an overwhelming sense of self-importance.

Trump has a gloomy pessimistic view of the world encapsulated in the philosophical vision that: "Man is the most vicious of all animals, and life is a series of battles ending in victory or defeat. You just can't let people make a sucker out of you." 134 Winning is all for one-dimensional Trump, the only purpose of life, the only thing worth pursuing, and the organizing principle of the Donald's existence. To win, Trump will do anything, raising the specter of what would a losing Trump do with nuclear weapons under his control, and what destruction might his unrestrained Ego and uncontrollable Id unleash upon the world if Trump is threatened in any sort of way. It is also worrisome to contemplate that Trump has developed a large following through his demagoguery and that authoritarian populism constitutes an American Nightmare, and a clear and present danger to US democracy and global peace and stability. 